\title{
Occurrence of urinary incontinence and function of pelvic floor muscles in athletes: a case series
}

\author{
DOI: https://doi.org/10.5114/pq.2018.75026
}

\author{
Bruna de Sousa Paganini, Franciele da Silva Pereira, Karoline Sousa Scarabelot, Janeisa Franck Virtuoso \\ Federal University of Santa Catarina, Araranguá, Santa Catarina, Brazil
}

\begin{abstract}
Introduction. To evaluate the prevalence of urinary incontinence (UI), as well as the function of pelvic floor muscles (PFM) in athletes.

Methods. An exploratory study was carried out among a series of cases composed of 15 amateur athletes from the municipality of Araranguá, Brazil. International Consultation on Incontinence Questionnaire - Short Form (ICIQ-SF) was used to identify the presence of UI, the absorbent test to verify the amount of urine leakage, and the PERFECT scheme to assess the function of PFM. The level of significance was $5 \%$.

Results. In ICIQ-SF, 46.7\% of the participants presented UI day by day and $6.7 \%(n=1)$ during sports practice. This demonstrated that, although they were symptomatic in the everyday life, during sports practice there were no urinary losses. When urinary loss was objectively measured, only 1 of the 4 assessed athletes presented a difference in weight greater than $2 \mathrm{~g}$. The strength of the PFM was shown to be optimal in all examined athletes $(n=3)$.

Conclusions. We have demonstrated that despite UI symptoms during the day, sports practice of mild to moderate intensity may contribute to a protective measure of the pelvic muscles, that is, physical exercise increases the strength of the PFM, bringing benefits to the amateur athlete. However, another research should be performed to make this correlation evident.

Key words: urinary incontinence, women, athletes, risk factor
\end{abstract}

\section{Introduction}

Current evidence suggests that among athletes, the risk of urinary incontinence $(\mathrm{UI})$ development is 3 times higher than in non-athletes [1, 2]. Although high-impact exercises have been identified as a risk factor for $\mathrm{UI}[3,4]$, research suggests that the frequency of sports training and the training time in years can also be considered important for UI [5, 6]. Among the studies performed with athletes, Da Roza et al. [5] observed significant associations between training volume and UI severity, demonstrating that the greater the training volume, the greater the severity of the symptoms.

The prevalence rate of UI in athletes can vary from $0 \%$ to $80 \%$ [7]. This wide range of variation comes mainly from the definition of physical exercise [8]. After all, it is known that some sports exercises, such as volleyball, provide greater impact on the volume of pelvic floor muscles (PFM) [9]. Вø [10] proposes two hypotheses that relate the physical exercise and the PFM. The first hypothesis suggests that during physical exercise, there is an increase in intra-abdominal pressure and a pre-contraction, which, consequently, affect the PFM. The second hypothesis indicates the impact of the body soil on weakening PFM.

A study by Jácome et al. [11] demonstrated that UI, although prevalent among athletes, is not an openly discussed condition, which justifies the lack of interest of units in relation to the therapeutic proposals that treat and prevent UI. Thus, the objective of this study is to analyse the occurrence of UI, as well as the function of the PFM in athletes.

\section{Subjects and methods}

This study is a series of cases, whose sample was composed of 15 amateur athletes from the city of Araranguá, Brazil. The sample consisted of the athletes who accepted to participate in the research and who did not meet the exclusion criteria. Included in the study were nulliparous women, 18-34 years of age, who practised amateur sports with regular training and participated in at least one competition per year. We excluded women with symptoms of urinary tract infection, such as pain or burning during urination, pregnant women, women who underwent hysterectomy, and those who presented with medical contraindications for evaluation.

To let us verify urinary loss situations, the participants answered the following questions, developed by the researcher: (a) Do you lose urine during sports? (b) Do you lose urine during competitions? (c) Do you use absorbents or any other form of protection during sports? (d) Do you use absorbents or any other form of protection during competition? The affirmative answer to these questions determined the presence of UI during training and competition, as well as the need for protection on these occasions. The International Consultation on Incontinence Questionnaire - Short Form (ICIQ-SF) [12] was used to determine the occurrence of day-to-day urinary loss. This questionnaire was applied only to collect this variable.

As for the sport, the participants were asked about the type of sport, practice time, weekly frequency, duration of training, practice of another modality and type of training. In addition, sociodemographic data such as age, marital status, schooling and profession were collected to characterize the sample. The instrument was developed by researchers.

Correspondence address: Franciele da Silva Pereira, Federal University of Santa Catarina, Pedro Rosalino Corrêa, no 48, Coloninha, Araranguá, Brazil, e-mail: franciele.pereira@posgrad.ufsc.br

Received: 2017.09.16

Accepted: 2018.01 .04

Citation: de Sousa Paganini B, da Silva Pereira F, Scarabelot KS, Virtuoso JF. Occurrence of urinary incontinence and function of pelvic floor muscles in athletes: a case series. Physiotherapy Quarterly. 2017;25(2):29-32; doi: https://doi.org/10.5114/pq.2018.73366. 
The objective urinary loss was verified in the training, through the absorbent test. The participants used a hygienic absorbent previously weighed on precision scales. They were informed to empty the bladder and to place the hygienic absorbent in the perineal region, next to the external urethral meatus. At the end of the training, the absorbent was weighed again. Weight difference greater than or equal to $2 \mathrm{~g}$ was considered urinary loss, following the recommendations established by Ghoniem et al. [13]. We also evaluated the subjective perception of effort during training with the modified Borg scale.

The subjective function of the PFM was evaluated with the use of the PERFECT scheme [14]. In this examination, vaginal examination was performed in order to quantify the intensity, duration, and sustentation of the PFM contraction.

The collected data were stored in a database with the Microsoft Excel ${ }^{\circledR}$ program and each participant was registered in accordance with a number encoder. Statistical analysis was performed with the Statistical Package for Social Sciences (SPSS) (version 17.0).

Initially, all variables were descriptively analysed with the use of simple frequency and percentages (categorical variables) and position and dispersion measures (numerical variables).

\section{Ethical approval}

The research related to human use has been complied with all the relevant national regulations and institutional policies, has followed the tenets of the Declaration of Helsinki, and has been approved by the Human Research Ethics Committee of the Federal University of Santa Catarina, under protocol number CAAE 53023716.0.0000.0121.

\section{Informed consent}

Informed consent has been obtained from all individuals included in this study.

\section{Results}

The total od 15 amateur athletes participated: softball $(n=4)$, soccer $(n=3)$, handball $(n=2)$, and volleyball $(n=6)$ players. The average age of the athletes was $23.9( \pm 4.0)$ years. As for the sociodemographic data, the athletes were predominantly singles $(n=14)$ and had graduated from a high school $(n=9)$.

Regarding training-related data, the practice time in the modality equalled $4.6( \pm 4.4)$ years and the training duration was $2.4( \pm 1.0)$ hours. In relation to the frequency of the sports practice, 8 athletes performed their activities once a week. In the total sample, $40 \%(n=6)$ of the participants performed running for more than 30 minutes, 20\% $(n=3)$ underwent speed training, and $40 \%(n=6)$ practised jumping.

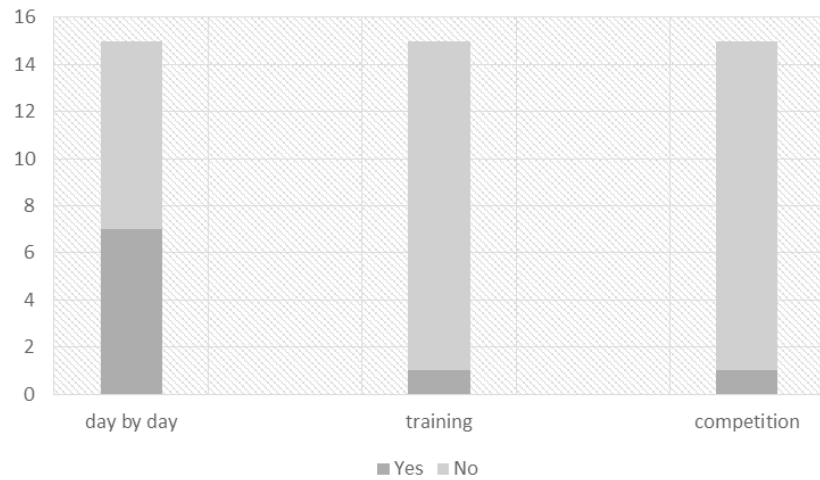

Figure 1. Comparison of proportions of amateur athletes who presented urinary loss on a daily basis, during training, and during competition

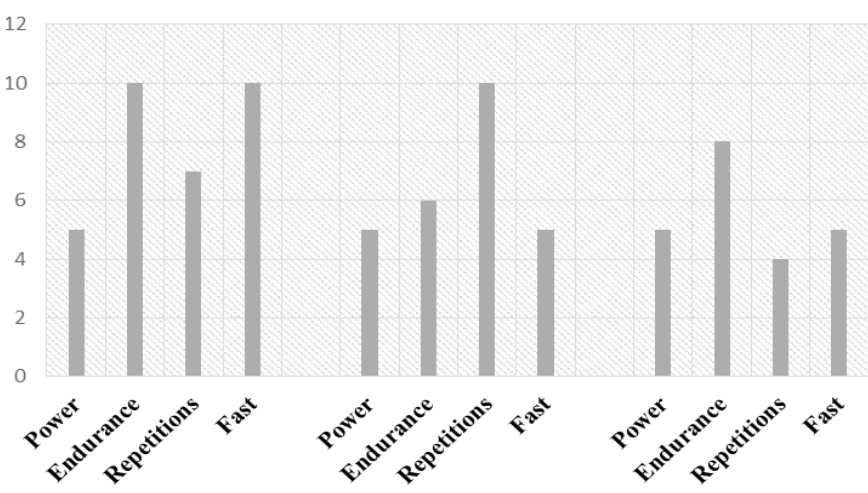

Figure 2. Results for the function of the pelvic floor muscles through the PERFECT scheme

Figure 1 presents the proportions of participants who presented urinary loss on a daily basis, during training, and during competition.

Regarding objective urinary loss, only 4 athletes performed this evaluation; among them, only 1 participant presented an absorbent weight difference greater than $2 \mathrm{~g}$. This was observed by subtracting the initial weight of the absorbents from the final values. Literature indicates loss of urine when the difference is greater than $2 \mathrm{~g}$. With reference to the subjective sensation of effort, the same athlete, when compared with the others, presented the Borg scale value above 6 (Table 1).

In relation to athlete 4 in Table 1, who obtained the highest rate of urinary loss, it is worth mentioning that she had been practicing the modality for about 12 years, concomitantly performing athletics.

All participants could undergo the evaluation of the pelvic floor; however, out of the 15 amateur athletes, 3 took part in the PFM assessment. None of these 3 athletes presented urinary loss. Regarding the variables of the PFM function, measured subjectively through the PERFECT scheme, all the

Table 1. Values of objective urinary loss, physical exertion during the modality, and practice time of amateur athletes who underwent objective urinary loss measurement $(n=4)$

\begin{tabular}{|c|c|c|c|c|c|c|}
\hline Athlete & Initial absorbent weight $(\mathrm{g})$ & Final absorbent weight $(\mathrm{g})$ & Final/initial relationship $(\mathrm{g})$ & Borg scale & Modality & Practice time \\
\hline 1 & 15.43 & 17.04 & 1.61 & 6 & Volleyball & 10 years \\
\hline 2 & 15.05 & 16.19 & 1.15 & 3 & Volleyball & 3 years \\
\hline 3 & 15.32 & 17.22 & 1.9 & 5 & Volleyball & 5 months \\
\hline $4^{*}$ & 15.09 & 17.57 & 2.48 & 7 & Soccer & 12 years \\
\hline
\end{tabular}


athletes performed the PFM contraction in a conscious way, so, according to the modified Oxford scale, all reached muscular strength level 5. In Figure 2, the values reached by the individual athletes are presented. It can be observed that in general, the values related to the repetition of the contractions maintained (endurance) and fast contractions (fast) were considered satisfactory, ranging from 6 to 10 seconds and from 5 to 10 repetitions, respectively.

\section{Discussion}

As observed in the present study, $46.7 \%(n=7)$ of the amateur athletes of Araranguá presented UI during the day, while when practising sport, only 1 athlete reported urinary loss during competition ( $n=1)$ and 1 during sports $(n=1)$. Regarding the function of the PFM, the findings of the study indicate that amateur athletes presented satisfactory strength of this musculature.

As in the present study, Salvatore et al. [15] also identified the prevalence of UI in amateur athletes. The authors point out that $31.7 \%$ of the athletes presented urinary loss during sports practice and $47.5 \%$ only on a daily basis, with $29.8 \%$ reporting the symptom in both situations. This information confirms that in athletes who practise mild to moderate exercise, although they have symptoms of daily urinary loss, the prevalence decreases during sports practice. However, in the present study, this cannot be confirmed as there was no comparison with exercises of other intensities.

Some studies indicate that the practice of physical activity is a risk factor for the development of $\mathrm{UI}$ in women, especially during efforts [16, 17]. However, Bø [10] reports that simultaneously with increased intra-abdominal pressure during exercise, a reflex contraction of the PFM occurs. Thus, other study designs can identify if the physical activity practice of mild to moderate intensity contributes to a better function of PFM, reducing urinary loss during exercise. In addition to the protective measure for PFM, practising physical exercises proposed for the health of women is already established in the literature [2].

The subjective evaluation of the PFM of the athletes in this research was considered satisfactory; this result becomes positive in accordance with the findings of Da Roza et al. [18], who found a moderate correlation between the Oxford scale and manometry, an important objective measure for the pelvic floor. In this sense, Silva et al. [19], as well as the results of the present study, showed greater PFM strength in female athletes when compared with sedentary women. These results can be explained by high vaginal pressure $\left(70.1 \pm 2.4 \mathrm{~cm} \mathrm{H}_{2} \mathrm{O}\right)$ observed in the study by Araujo et al. [20], demonstrating that a strong pelvic floor counterbalances increases in the intra-abdominal pressure occurring during high-impact activities, constituting a protection from dysfunctions bound with pelvic muscle weakness.

It is also highlighted in this series of cases that the athlete who presented the value greater than $2 \mathrm{~g}$ in the absorbent after the sports practice in the objective evaluation of urinary loss also reported a physical effort, on the Borg scale, higher than the other participants, in addition to practising the modality for 12 years and partaking in other modalities, such as athletics and running. In this case, the urinary loss can be explained by the high rate of physical effort and the practice of modalities that can generate a force of reaction to the ground that increases in 16 times the body weight [21].

In this sense, we can still mention the study by Araujo et al. [22], who evaluated urinary loss in long-distance runners and concluded that UI did not occur owing to the high impact of this modality, but as a result of muscle fatigue, so that more than $60 \%$ of these athletes reported losses during training and during competition. These premises can objectively explain the occurrence of urinary loss in the athlete who practised more than one modality.

\section{Limitations}

Among the limitations of the study, there is the small number of athletes in the research, which makes the results little possible to generalize, although they are important to identify the benefits of physical exercise to the pelvic floor. In addition, the authors could identify the diversity of the modalities practised by the athletes, as well as the lack of specificity in evaluating only one modality, although these results have demonstrated that the greater the sports diversity, the more prone the pelvic floor will be to suffer damage to its muscles. Therefore, we suggest studies that would identify the prevalence of $\mathrm{UI}$ and factors related to sports practice in a specific way. A review by Nygaard et al. [2] points out that although they present studies that relate UI to physical exercise, prospective research in this population should be performed to help discover the causality of the symptoms. In this way, it will be possible to create prevention strategies and treatment methods effective for athletes' performance depending on their modality.

\section{Conclusions}

As the studied athletes were UI symptomatic on a daily basis, protective measures seem important. The study identified the benefits of moderate to low intensity physical exercise, which increases the strength of the PFM.

It is also worth noting the need for new studies to better elucidate the advantages of physical exercise in UI, as well as to develop prevention strategies so that these losses do not occur. This sports practice, which may favour athlete adherence and increased performance, will minimize the negative impact of UI on the quality of life.

\section{Disclosure statement}

No author has any financial interest or received any financial benefit from this research.

\section{Conflict of interest}

The authors state no conflict of interest.

\section{References}

1. Carvalhais A, Natal JR, Bø K. Performing high-level sport is strongly associated with urinary incontinence in elite athletes: a comparative study of 372 elite female athletes and 372 controls. Br J Sports Med. 2017; doi: 10.1136/ bjsports-2017-097587.

2. Nygaard IE, Shaw JM, Bardsley T, Egger MJ. Lifetime physical activity and female stress urinary incontinence. Am J Obstet Gynecol. 2015;213(1):40.e1-e10; doi: 10.1016/j.ajog.2015.01.044.

3. Dias N, Peng Y, Khavari R, Nakib NA, Sweet RM, Timm GW, et al. Pelvic floor dynamics during high-impact athletic activities: a computational modeling study. Clin Biomech. 2017;41:20-27;doi:10.1016/j.clinbiomech.2016.11.003.

4. Hagovska M, Švihra J, Buková A, Hrobacz A, Dračková D, Švihrová V, et al. Prevalence of urinary incontinence in females performing high-impact exercises. Int J Sports Med.2017;38(3):210-216;doi:10.1055/s-0042-123045. 
5. Da Roza T, Brandão S, Mascarenhas T, Jorge RN, Duarte JA. Urinary incontinence and levels of regular physical exercise in young women. Int J Sports Med. 2015; 36(9):776-780; doi: 10.1055/s-0034-1398625.

6. Martins LA, Dos Santos KM, Albano Dorcinio MB, Alves JO, Da Roza T, Tonon da Luz SC. Is urine loss influenced by type of sport or training load? A systematic review [in Portuguese]. Rev Bras Med Esporte. 2017;23(1):7377; doi: 10.1590/1517-869220172301163216.

7. Eliasson K, Larsson T, Mattsson E. Prevalence of stress incontinence in nulliparous elite trampolinists. Scand J Med SciSports.2002;12(2):106-110;doi:10.1034/j.1600-0838. 2002.120207.x.

8. Bø K, Braekken IH, Majida M, Engh ME. Constriction of the levator hiatus during instruction of pelvic floor or transversus abdominis contraction: a 4D ultrasound study. Int Urogynecol J Pelvic Floor Dysfunct. 2009;20(1):2732; doi: 10.1007/s00192-008-0719-3.

9. Rimstad L, Larsen ES, Schiøtz HA, Kulseng-Hanssen S. Pad stress tests with increasing load for the diagnosis of stress urinary incontinence. Neurourol Urodyn. 2014; 33(7):1135-1139; doi: 10.1002/nau.22460.

10. Bø K. Urinary incontinence, pelvic floor dysfunction, exercise and sport. Sports Med. 2004;34(7):451-464; doi: 10.2165/00007256-200434070-00004.

11. Jácome C, Oliveira D, Marques A, Sá-Couto P. Prevalence and impact of urinary incontinence among female athletes. Int J Gynaecol Obstet. 2011;114(1):60-63; doi: 10.1016/j.ijgo.2011.02.004.

12. Tamanini JT, Dambros M, D'Ancona CA, Palma PC, Rodrigues Netto N Jr. Validation of the "International Consultation on Incontinence Questionnaire - Short Form" (ICIQ-SF) for Portuguese [in Portuguese]. Rev Saude Publica. 2004;38(3):438-444; doi: 10.1590/S0034-891 02004000300015.

13. Ghoniem G, Stanford E, Kenton K, Achtari C, Goldberg R, Mascarenhas T, et al. Evaluation and outcome measures in the treatment of female urinary stress incontinence: International Urogynecological Association (IUGA) guidelines for research and clinical practice. Int Urogynecol J Pelvic Floor Dysfunct. 2008;19(1):5-33; doi: 10.1007/ s00192-007-0495-5.

14. Bø K, Larsen S, Kvarstein B, Hagen RH. Classification and characterization of responders to pelvic floor muscle exercise for female stress urinary incontinence. Neurourol Urodyn. 1990;9(4):395-397.

15. Salvatore S, Serati M, Laterza R, Uccella S, Torella M, Bolis PF. The impact of urinary stress incontinence in young and middle-age women practising recreational sports activity: an epidemiological study. Br J Sports Med. 2009;43(14):1115-1118; doi:10.1136/bjsm.2008.049072.

16. Thyssen $\mathrm{HH}$, Clevin L, Olesen S, Lose G. Urinary incontinence in elite female athletes and dancers. Int Urogynecol J Pelvic Floor Dysfunct. 2002;13(1):15-17; doi: 10.1007/s001920200003.

17. Bø K, Borgen JS. Prevalence of stress and urge urinary incontinence in elite athletes and controls. Med Sci Sports Exerc. 2001;33(11):1797-1802; doi: 10.1097/ 00005768-200111000-00001.

18. Da Roza T, Natal JR, Mascarenhas T, Duarte JA. Urinary incontinence in sport women: from risk factors to treatment - a review. Curr Wom Health Rev. 2013;9(2):7784; doi: 10.2174/157340480902140102152031.

19. Silva LH, Serezuella KC, Bordini A, Citadini JM. The relationship between stress urinary incontinence and exercises in nulliparous women [in Portuguese]. Salusvita. 2005;24(2):195-218.
20. Araujo MP de, Parmigiano TR, Della Negra LG, Torelli L, Carvalho CG de, Wo L, et al. Evaluation of athletes' pelvic floor: is there a relation with urinary incontinence? [in Portuguese]. Rev Bras Med Esporte. 2015;21(6):442446; doi: 10.1590/1517-869220152106140065.

21. Caetano AS, Tavares MCGCF, Lopes MHBM. Urinary incontinence and physical activity practice [in Portuguese]. Rev Bras Med Esporte. 2007;13(4):270-274; doi: 10.1590/ S1517-86922007000400012.

22. Araujo MP, Oliveira E, Zucchi EV, Trevisani VF, Girão MJ, Sartori MG. The relationship between urinary incontinence and eating disorders in female long-distance runners [in Portuguese]. Rev Assoc Med Bras. 2008;54(2):146-149; doi: 10.1590/S0104-42302008000200018. 